\title{
Numerais na língua Mehináku (Arawak)
}

DOI: http://dx.doi.org/10.21165/el.v48i2.2231

\section{Paulo Henrique Pereira Silva de Felipe ${ }^{1}$}

\section{Resumo}

Nosso objetivo, neste trabalho, é apresentar uma breve descrição linguística do sistema numeral, ou seja, dos termos numéricos, na língua Mehináku (Arawak). Evidenciaremos, em especial, o modo de funcionamento do sistema de contagem nessa língua. Pela análise da língua Mehináku que fizemos até o momento, percebemos que essa língua apresenta 20 números, que correspondem aos dedos das mãos e dos pés, respectivamente, sendo somente três números autônomos e com radicais completamente distintos. São eles: pawitsa (um), mipiama (dois) e kamayukula (três). Todos os demais números são derivados destes primeiros. Mostraremos, ainda, informações relativas ao plural e ao coletivo, bem como os recursos neológicos criados pelos falantes da língua Mehináku para tratar de valores em dinheiro.

Palavras-chave: língua Mehináku; sistema numeral; línguas indígenas; família Arawak.

1 Universidade Estadual de Campinas (UNICAMP), Campinas, São Paulo, Brasil paulohdefelipe@gmail.com; https://orcid.org/0000-0001-6607-5417 


\title{
Numerals in Mehináku language (Arawak)
}

\begin{abstract}
Our goal, in this paper, is to present a brief description of the linguistic numeral system, i.e., the numerical terms in Mehináku (Arawak) language. In particular, we will show the operating mode of the counting system in that language. By the analysis of the Mehináku language that we have done so far, we notice that this language features 20 numbers, corresponding to the fingers and toes, respectively, being only three autonomous numbers and with completely distinct radicals: pawitsa (one), mipiama (two) and kamayukula (three). All other numbers are derived from these first numbers. We will also show information about the plural and the collective, as well as the neological resources created by the Mehináku natives to refer to cash values.
\end{abstract}

Keywords: Mehináku language; numeral system; indigenous language, Arawakan language family.

\section{Considerações iniciais ${ }^{2}$}

Os sistemas numerais das línguas do mundo podem variar muito. Há línguas nas quais os sistemas numerais são infinitos, enquanto há outras cujo limite de contagem pode variar entre um, dois, três, dez, e assim por diante. É por conta dessa variedade de possibilidades, aliás, que os numerais podem figurar de maneiras tão diversas nas estruturas das línguas. É possível encontrar, por exemplo, línguas em que cada termo numérico possui mais de cem formas, como no Palikúr (GREEN, 1997), até línguas em que não há termos numéricos específicos, como no Canela (POPJES; POPJES, 1986), em que a contagem é feita por meio de termos gerais como "um par", "alguns", "muitos", e assim por diante.

Para além dessas características dos numerais, eles ainda podem concordar em gênero com o substantivo a que se referem e indicar a posição referencial ou direcional de certos nomes (vertical, horizontal, sentado, saindo, chegando), como no Kadiwéu. As línguas podem, além disso, apresentar uma diversidade de classificadores numéricos, como no Waurá, Kampa, Tariana, Werekena etc. (AIKHENVALD, 1994).

É importante destacar que o fato de um povo contar até 10, por exemplo, não quer dizer que este povo seja primitivo, em comparação a um outro que conte além dos trilhões. Pelo contrário, os sistemas numerais estão submetidos, simplesmente, às necessidades de cada povo/cultura.

2 Este trabalho tem apoio da Fundação de Amparo à Pesquisa do Estado de São Paulo (Processo $n^{\circ}$ 2016/18391-4). 
Neste trabalho iremos mostrar, mesmo que brevemente, dado o caráter inicial da pesquisa, como são os numerais em Mehináku, bem como iremos apresentar algumas formas gramaticais da língua, usadas para indicar plural e coletivo. Mostraremos, também, como se dá o processo de contagem de dinheiro em Mehináku, sobretudo porque queremos evidenciar o recurso neológico usado pelos falantes para denominar itens alóctones.

\section{A língua e o povo Mehináku}

Os índios Mehináku do Brasil central são, segundo Gregor (1982), um dos vários grupos de indígenas que vivem e compõem aldeias muito similares ao longo dos formadores do rio Xingu, um dos grandes tributários do Amazonas. De acordo com o Instituto Socioambiental (ISA, 2006), os Mehináku são habitantes da área cultural conhecida como Alto Xingu e fazem parte de um amplo complexo de povos que, embora compartilhem de muitas semelhanças, em especial em relação à língua e a cultura, são diferentes entre si.

Os Mehináku falam uma língua de mesmo nome, ${ }^{3}$ pertencente à família Arawak. Ainda de acordo com o ISA (2006), estima-se que a língua Mehináku seja falada por aproximadamente 250 pessoas que habitam a região do rio Kurisevo, no Parque Indígena do Xingu, Mato Grosso, Brasil. Em pesquisas de campo recentes, entretanto, percebemos que esse número está desatualizado, uma vez que somente na aldeia Utawana há cerca de 180 indígenas. Acreditamos, portanto, que a língua Mehináku seja falada, atualmente, por mais de 400 indígenas no total.

A população distribui-se em quatro aldeias, são elas: (i) Uyaipiyuku, que é a mais antiga e da qual derivaram as demais aldeias, e que é dirigida pelo cacique Yumui Mehináku; (ii) Utawana, que desde o início de 2016 tem sido dirigida pelo cacique (e também pajé) Tukuyari; (iii) Kaupüna, que foi criada por Makaulaka Mehináku, filho de Yahati Mehináku (antigo cacique da aldeia Utawana), após ter retornado da Universidade de Brasília, onde fez seu mestrado em Linguística e (iv) Aturua, atualmente dirigida pelo cacique Amunai, irmão do cacique da aldeia Uyaipiyuku. A aldeia Utawana é a mais próxima da cidade, localizada a cerca de 35 quilômetros da cidade de Gaúcha do Norte (MT) e mantém certa proximidade com as aldeias Kaupüna e Aturua, de modo que é possível se locomover de uma a outra mais rapidamente, seja por meio de carro, na época da seca, ou por barco, na época da cheia do rio Kurisevo. A aldeia Uyaipiyuku, por sua vez, é a mais distante das quatro mencionadas acima, e está situada a aproximadamente 4 horas de viagem de barco da aldeia de Utawana.

3 De acordo com os indígenas, Mehináku é o nome dado pelo "homem branco" à língua, em virtude de sua dificuldade em pronunciar adequadamente o nome da língua que, segundo eles, é Imiehünaku (como escrito ortograficamente na língua). 
Nossa pesquisa de campo foi feita na aldeia Utawana, segunda maior entre as quatro aldeias habitadas por povos Mehináku. A aldeia tem 11 casas dispostas em formato de círculo, e outras duas casas que ficam próximas à base de enfermagem. As 11 casas que compõem o círculo que forma o coração da aldeia são construídas com madeira e forradas com uma espécie de palha, encontrada nas proximidades. As duas casas que estão fora do círculo são feitas de madeira. Além das casas habitadas pelas famílias Mehináku, há, ainda, uma casa mais afastada e a menor de todas, destinada ao uso escolar.

De acordo com Corbera Mori (2008), à diferença do que ocorre em alguns outros povos indígenas, no caso do Mehináku há uma correlação entre o número da população e o número de falantes. Todos os membros das quatro aldeias Mehináku falam a língua materna. Os homens de mais de 60 anos são monolíngues, falam apenas a língua indígena. Do mesmo modo, as mulheres mais adultas só falam em Mehináku. As mulheres mais jovens entendem o português, mas o falam muito pouco. Os jovens, ao contrário, falam o português com certa fluidez. Contudo, quando saem para vender artesanato em cidades como Campinas, São Paulo, Brasília, entre outras, gostam de falar em sua própria língua.

\section{Sistemas numerais em Mehináku}

\subsection{Os numerais}

O sistema de contagem na língua Mehináku é relativamente abrangente, uma vez que é possível contar, nesta língua, até o número 20 (vinte). Esse sistema de contagem reflete o número de dedos dos falantes, ou seja, os índios Mehináku dão nomes para os números até o limite de dedos que eles têm nas mãos e nos pés.

Além disso, dos 20 (vinte) números para os quais é possível encontrar referência em Mehináku, consideramos que somente 3 (três) deles, os primeiros três (1 a 3), são básicos ou autônomos, ou seja, não derivam de nenhum outro número. A partir do número 3, considerando de 4 a 20, portanto, todos os números são derivações ou combinações dos três primeiros números com outras formas da língua.

No que concerne aos primeiros 10 números, estes referem-se aos dedos das mãos dos falantes, e os Mehináku costumam sempre contar do polegar em direção ao dedo mínimo, primeiro na mão esquerda, e, depois, na direita, conforme mostramos na Figura 1, a seguir: 


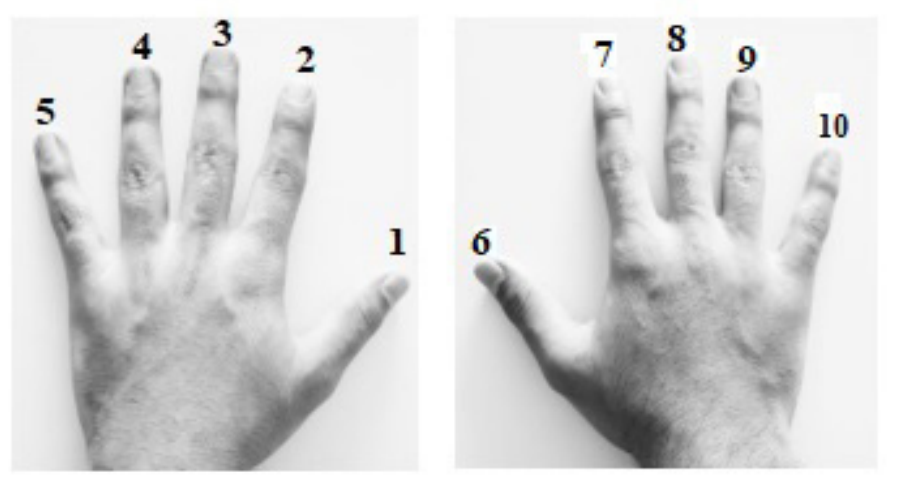

Figura 1. Esquema de contagem nas mãos (1 a 10) em Mehináku

Fonte: Sistema de contagem na língua Mehináku.

Como dissemos, somente os três primeiros números, aqueles correspondentes aos dedos polegar, indicador e médio da mão esquerda, são básicos em Mehináku. Vejamos, em (1), abaixo, como estes números são nomeados:

(1)
Número 1
Número 2
Número 3
a. pawitsa
'um/uma'
b. mipiama
'dois/duas'
c. kamayukula
'três'

Outra informação interessante em relação a esses números é que, quando em sintagmas nominais, eles não concordam em gênero com os nomes que os acompanham, como em português, por exemplo. É possível ver isso pelos exemplos em (2), em que os números não recebem nenhum tipo de marcação morfológica indicando o sexo do referente, seja no singular ou no plural:

(2)
a. pawitsa enisa
um homem
'um homem'
b. pawitsa tinesu
uma mulher
'uma mulher'
c. mipiama enifa-naw
dois homem-PL
'dois homens'
d. mipiama tinesu-naw
duas mulher-pL
'duas mulheres'
e. pawitsa jamukutipa- $\varnothing$
um jovem-MASC
'um jovem'
um jovem-FEM
'uma jovem'
f. pawitsa jamukutipa-lu
g. mipiama jamukutipa- Ø-naw
dois jovem-MASC-PL
'dois jovens (rapazes)'
h. mipiama jamukutipa-lu-naw
dois jovem-FEM-PL
'duas jovens (moças)'


Os demais números, como dissemos, são derivados desses três primeiros ou formados a partir da junção deles com outras formas da língua. Ainda no que se refere aos dedos das mãos, vejamos agora como são denominados, em Mehináku, os números de 4 a 10.

\title{
(3) Número 4
}

mipiama-wa-ka

dois-ADIT-CL.largo

'quatro' (Literalmente: dois alargado)

\section{(4) Número 5}

\author{
pawitsa wišikũ-i \\ um mão-N.POSS \\ 'cinco' (Literalmente: uma mão)
}

\section{(5) Número 6}

pawitsa taputa wişikũ-i

um atravessar mão-N.Poss

'seis' (Literalmente: um que atravessa a mão)

\section{(6) Número 7}

\author{
mipiama taputa wişikũ-i \\ dois atravessar mão-N.Poss \\ 'sete' (Literalmente: dois que atravessa a mão)
}

\section{(7) Número 8}

$$
\begin{aligned}
& \text { kamayukula taputa wişikũ-i } \\
& \text { três atravessar mão-N.Poss } \\
& \text { 'oito' (Literalmente: três que atravessa a mão) }
\end{aligned}
$$

\section{(8) Número 9}

$$
\begin{aligned}
& \text { mipiama-wa-ka taputa wişikũ-i } \\
& \text { dois-ADIT-CL.largo atravessar mão-N.Poss } \\
& \text { 'nove' (Literalmente: quatro que atravessa a mão) }
\end{aligned}
$$

\section{(9) Número 10}

$$
\begin{aligned}
& \text { mamala wisikũ-i } \\
& \text { acabar/terminar mão-n.poss } \\
& \text { 'dez' (Literalmente: acabaram as mãos) }
\end{aligned}
$$

Os números de 11 a 20 seguem a mesma lógica dos números apresentados acima, mas, como mencionamos, fazem referência aos dedos dos pés dos falantes. Por esta razão, os Mehináku costumam contar, também, do polegar em direção ao dedo mínimo, primeiro no pé esquerdo e, depois, no direito, conforme mostramos na Figura 2: 

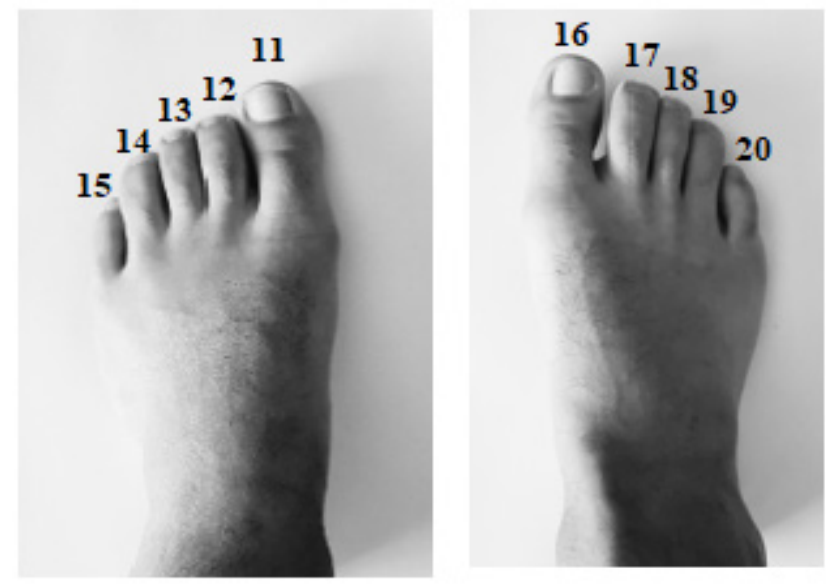

Figura 2. Esquema de contagem nos pés (11 a 20) em Mehináku

Fonte: Sistema de contagem na língua Mehináku

Vimos, acima, que, na construção dos termos para os números de 1 a 10, os falantes somente utilizam a palavra wişikũ-i "mão", a partir do número 5. Na construção dos termos para contagem dos números de 11 a 20, por outro lado, os falantes lançam mão do termo kitsapa-i, que corresponde à palavra "pé-N.Poss", desde a construção do número 11.

Acreditamos que este recurso é utilizado para evitar a homonímia e, consequentemente, a ambiguidade, uma vez que usar somente o termo pawitsa "um" para classificar o número 11, primeiro número a ser contado no pé esquerdo, poderia fazer com que este termo fosse confundido com o número "um", primeiro número da mão esquerda. Vejamos, abaixo, como são construídos os números de 11 a 20 em Mehináku:

\section{(10) Número 11}

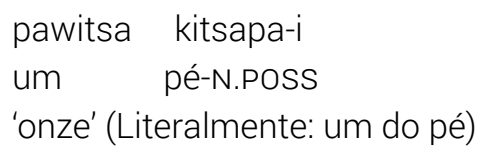

(11) Número 12
mipiama kitsapa-i
dois pé-N.POSS
'doze' (Literalmente: dois do pé)

\section{(12) Número 13}
kamayukula kitsapa-i
três pé-N.POSS
'treze' (Literalmente: três do pé) 
(13) Número 14

mipiama-wa-ka kitsapa-i
dois-ADIT-CL.LARGo pé-N.POSS
'quatorze' (Literalmente: quatro do pé)

(14) Número 15

mamala wişikũ-i pawitsa mamala kitsapa-i

acabar/terminar mão-n.poss um acabar/terminar pé-n.poss

'quinze' (Literalmente: acabou as mãos e um dos pés)

O número 15 é um caso interessante dentre os termos criados pelos Mehináku para a contagem. Ele, diferente dos demais números, é constituído tanto da palavra wişikũ-i 'mão-N.Poss', quanto da palavra kitsapa-i 'pé-N.Poss'. Os falantes utilizam uma construção como esta porque querem deixar claro que, literalmente, acabou a mão, e, também, um pé, ou seja, acabaram os 10 dedos das mãos e, também, os 5 primeiros dedos do pé esquerdo, totalizando 15 unidades.

Do número 16 até o 19, segue-se a mesma lógica do 6 ao 9, acrescentando o verbo taputa "atravessar" à construção numeral. O número 20, por seu turno, segue a lógica do número 10, sendo construído por meio do verbo mamala "acabar/terminar".

\section{(15) Número 16}

pawitsa taputa kitsapa-i

um atravessar pé-N.POSS

'dezesseis' (Literalmente: um que atravessa o pé)

(16) Número 17

mipiama taputa kitsapa-i
dois atravessar pé-N.Poss
'dezessete' (Literalmente: dois que atravessa o pé)

(17) Número 18

kamayukula taputa kitsapa-i

três atravessar pé-N.Poss

'dezoito' (Literalmente: três que atravessa o pé)

(18) Número 19

mipiama-wa-ka taputa kitsapa-i

dois-ADIT-CL.LARGO atravessar pé-N.POSS

'dezenove' (Literalmente: quatro que atravessa o pé) 


\section{(19) Número 20}
mamala kitsapa-i
acabar/terminar pé-N.Poss
'vinte' (Literalmente: acabaram/terminaram os pés)

Para expressar quantidades acima de 20 unidades, os falantes utilizam, atualmente, quantificadores como amunuia, que significa "muitos", "vários". Em conversa pessoal com os indígenas, porém, alguns nos disseram que, antigamente, era possível contar até o número 40 na língua. De acordo com eles, o número 40 era representado da seguinte forma:

\section{(20) Número $\mathbf{4 0}$}

$\begin{array}{lll}\text { mamala ni-kitsapa } & \text { mamala pi-kitsapa } \\ \text { acabar/terminar } & \text { 1SG-pé } & \text { acabar/terminar 2sG-pé }\end{array}$

'quarenta' (Literalmente: acabaram/terminaram os meus pés e acabaram/terminaram os seus pés (os do interlocutor))

É oportuno observar este exemplo, porque ele nos revela uma questão interessante a respeito do sistema de contagem/numeral em Mehináku: o fato de que os falantes utilizam não somente seus próprios dedos das mãos e dos pés para contar, como também os dedos dos pés e das mãos do interlocutor, da pessoa com quem se conversava. Em outras palavras, era possível referir-se tanto aos dedos do locutor quanto do interlocutor, antigamente, em Mehináku, para se estabelecer relações matemáticas de contagem.

Hoje em dia, entretanto, embora tenhamos apresentado os 20 números presentes na língua Mehináku e ainda a possibilidade antiga de contar até 40, poucos falantes continuam utilizando todos esses números. Em geral, por conta da influência da língua portuguesa e da saída dos indígenas das aldeias para a venda de artesanato nas cidades, os falantes Mehináku tendem a contar, no máximo, até o 10 na sua língua, sendo as quantidades superiores a estas contadas em português.

\subsection{Plural}

Ainda no que se refere à categoria de número, há duas formas, em Mehináku, utilizadas pelos falantes para marcar o plural dos nomes, são elas: -naw $\sim-n e w^{4} \sim$ naw ${ }^{5}$ e -tipe. 0 singular não é marcado morfologicamente (CORBERA MORI, 2007). O sufixo -naw -new

4 Há, aqui, um processo de harmonia vocálica, em que a vogal do sufixo de coletivo concorda em altura com a vogal da última sílaba do nome ao qual este sufixo está anexado.

5 Aqui ocorre a palatalização da nasal alveolar em contexto de vogal nasal. 
é utilizado para marcar o plural de entidades com os traços [+humano] [+animado] ${ }^{6}$, ou seja, os seres humanos, conforme é possível ver abaixo:

(21). -naw -new -naw: traços [+humano] [+animado]: seres humanos.

$\begin{array}{llll}\text { nutãĩ } & \text { 'meu filho' } & \text { nutãĩ-naw } & \text { 'meus filhos' } \\ \text { nitsapalu } & \text { 'minha filha' } & \text { nitsapalu-naw } & \text { 'minhas filhas' } \\ \text { nupawa } & \text { 'meu irmão' } & \text { nupawa-naw } & \text { 'meus irmãos' } \\ \text { nupene } & \text { 'meu parente' } & \text { nupene-naw } & \text { 'meus parentes' } \\ \text { tineșu } & \text { 'mulher' } & \text { tinesu-naw } & \text { 'mulheres' } \\ \text { enişa } & \text { 'homem' } & \text { enişa-naw } & \text { 'homens' }\end{array}$

O sufixo -tipe, por seu turno, é utilizado para marcar o plural de entidades com os traços [-humano] [+/-animado], ou seja, os animais em geral e alguns objetos que, embora [-animado], são muito próximos de seres humanos, que são [+animado] por natureza, motivo pelo qual acreditamos que eles recebam esse sufixo. Vejamos, a seguir, alguns dados de Corbera Mori (2007):

(22). -tipe: traços [-humano] [+/-animado]: animais em geral e alguns objetos muito próximos de seres animados.

$\begin{array}{llll}\text { itsa } & \text { 'canoa' } & \text { itsa-tipe } & \text { 'canoas' } \\ \text { watana } & \text { 'flauta' } & \text { watana-tipe } & \text { 'flautas' } \\ \text { araukumã } & \text { 'galinha' } & \text { araukumã-tipe } & \text { 'galinhas' } \\ \text { kupati } & \text { 'peixe' } & \text { kupati-tipe } & \text { 'peixes' }\end{array}$

\subsection{Coletivos}

Há também, em Mehináku, morfemas gramaticais utilizados para marcar coletivos, cuja função é assinalar que determinadas entidades do mundo podem ser reunidas em conjuntos maiores de entidades com as mesmas características. Estes morfemas, que aparecem sob a forma de sufixos anexados aos nomes, são: -pihi e -taku.

6 Estamos entendendo o traço [+/-animado] como aquele que se refere ao ser dotado/não dotado de movimento, ou seja, que pode ou não se movimentar de forma dinâmica. As plantas, embora sejam seres vivos (o que poderia levar-nos a classificá-las como [+animado], não se movimentam de forma dinâmica como o fazem os animais e seres humanos, motivo pelo qual elas são classificadas como [-animado]. 
O primeiro recai sobre o grupo com traços [-humano] [+animado], ou seja, os animais em geral. Vejamos:

(23). -pithì: traços [-humano] [+animado]: animais em geral.
a. autu
'porco do mato'
autu-pihi
'vara de porcos'
b. ainãma
'veado grande'
ainãma-pihì
'conjunto de veados'
c. awaiulukuma
'cachorro'
awaiulukuma-pihi
'matilha'
b. Jakalu
'papagaio'
Sakalu-pihi
'conjunto de papagaios'
b. Jukuti
'periquito'
Jukuti-pihi
'conjunto de periquitos'
b. kuri
'tipo de pássaro'
kuri-pihi
'conjunto de pássaros'

O segundo recai sobre aquelas entidades do mundo com os traços [-animado] [-humano], ou seja, as plantas. Poderíamos pensar que, classificando as plantas com os traços [-animado] [-humano], não as estaríamos distinguindo dos objetos, por exemplo. De fato, esta seria uma verdade se os objetos recebessem sufixos de coletivo. Como não há coletivo de objetos em Mehináku, optamos por manter esses traços para os coletivos de plantas. O sufixo -taku é um morfema classificador locativo, usado para, nesse sentido, assinalar o local onde está reunido o conjunto das unidades, conforme é possível ver a seguir:

(24). -taku: [-humano] [-animado]: plantas.
a. akãi
'pequi'
akãĩ-taku
'pequizal'
b. heseti
'amendoim'
heseti-taku
'amendoinzal'
c. wapalakuma
'abacaxi'
wapalakuma-taku
'abacaxizal'

O Quadro 1, abaixo, resume tanto as informações a respeito do plural quanto as informações referentes ao coletivo em Mehináku:

Quadro 1. Morfemas de plural e coletivo em Mehináku

\begin{tabular}{|l|l|l|}
\hline Morfema & Traços & Grupo a que se referem \\
\hline -naw & [+humano] [+animado] & Seres humanos. \\
\hline -tipe & [-humano] [+/-animado] & $\begin{array}{l}\text { Animais em geral e alguns objetos muito próximos de } \\
\text { seres animados. }\end{array}$ \\
\hline -pihi & [-humano] [+animado] & Animais em geral. \\
\hline -taku & [-humano] [-animado] & Plantas. \\
\hline
\end{tabular}

Fonte: Língua Mehináku. 


\subsection{Criações neológicas para contagem de dinheiro}

Por conta da frequente saída dos Mehináku para a cidade, em virtude da venda de seus artesanatos, os indígenas criaram neologismos para tratar dos valores em reais. Assim, cada cédula de real, ao ser inserida na cultura Mehináku, foi ressignificada, e recebeu um nome. Esse nome condiz com o tipo, a espécie do animal que está estampado em cada nota. Em outras palavras, o que os indígenas fizeram foi dar nomes às notas aproximando os animais estampados nas cédulas aos animais da fauna onde vivem ou com os quais têm contato mais frequente. Vejamos como se dá esse processo interessante:

(25) Cédula de 2 reais

trakaja-taku

tartaruga-CL.LOC

'dois reais (cédula)'

(26) Cédula de 5 reais

waiakapa-taku

garça-CL.LOC

'cinco reais (cédula)'

(27) Cédula de 10 reais

arara-taku

arara-CL.LOC

'dez reais (cédula)'

(28) Cédula de 20 reais

kapulukumã-taku

espécie de macaco preto (bugio)-cl.loc

'vinte reais (cédula)'

(29) Cédula de $\mathbf{5 0}$ reais

janumaka-taku

onça-CL.LOC

'cinquenta reais (cédula)'

(30) Cédula de $\mathbf{1 0 0}$ reais

hiaitsapa-taku

espécie de peixe (tucunaré)-CL.LOC

'cem reais (cédula)'

É interessante observar como foram criados dois dos exemplos apresentados acima: aquele usado para a nota de dois reais e aquele usado para a nota de dez reais. Nesses casos, veremos que os Mehináku não utilizam de nomes da sua língua para criar novos 
conceitos, mas emprestam nomes do Tupi, que estão incorporados, por sua vez, ao léxico do Português. Como tracajá e arara são palavras comuns na língua portuguesa, acreditamos que os falantes as utilizem como se as tivessem emprestado do português e não do Tupi. Durante uma das entrevistas para a coleta de dados, perguntamos a um dos falantes se ele sabia de onde vinham essas palavras e ele nos informou que vinham do português. Não estamos afirmando, obviamente, que os indígenas não saibam que essas palavras são de origem Tupi, uma vez que é muito provável que, sobretudo os mais velhos, saibam da origem de tais palavras. Como, todavia, essas palavras estão fortemente incorporadas ao léxico do português, é comum que os falantes mais jovens do Mehináku acreditem que elas venham diretamente do português.

O que queremos apontar, diante disso, é que o processo neológico utilizado pelos Mehináku para a caracterização do dinheiro lança mão não somente de recursos de sua própria língua, a exemplo da criação neológica, como também de empréstimos de outras línguas.

Para as moedas, os Mehináku criaram o termo taw-kaiaka ferro-redondo 'ferro redondo', e não há distinção entre os vários tipos de moedas. Eles atribuem o mesmo termo tanto para a moeda de um real, quanto para as menos valiosas, como a de dez e cinco centavos.

\section{Considerações finais}

Esperamos que este trabalho possa ter fornecido uma visão geral a respeito do sistema numeral em Mehináku, sobretudo no que se refere ao modo como os integrantes desse povo contam e, também, sobre os recursos que eles utilizam para codificar plural e coletivo na língua. Em trabalhos futuros, pretendemos explorar também a existência de numerais ordinais, que temos percebido na língua, bem como verificar como esses números ordinais, os números cardinais e os morfemas de plural e coletivo funcionam sintaticamente, observando, dentre outros aspectos, a ordem em que figuram na sentença.

\section{REFERÊNCIAS}

AIKHENVALD, A. Y. Classe nominal e gênero em línguas aruák, Boletim do Museu Paraense Emílio Goeldi-CNPq, Belém, v. 10, n. 2, p. 137-259, 1994.

CORBERA MORI, A. H. Aspectos da estrutura Nominal em Mehináku (Arawak). Estudos Linguísticos, São Paulo, v. XXXVI, n. 1, p. 253-257, jan.-abr. 2007.

CORBERA MORI, A. H. Aspectos da Morfofonologia e Morfologia nominal da língua Mehináku (Arawak). In: FRANCHETTO, B. Alto Xingu: uma sociedade multilíngue. Rio de Janeiro: Museu do índio- FUNAI, 2011. p. 193-216. 
CORBERA MORI, A. H. Waurá e Mehináku: um breve estudo comparativo. Estudos linguísticos, São Paulo, v. 41, n. 1, p. 196-205, jan.-abr. 2012.

FARGETTI, C. M.; SUMAIO, P. A. Numerais in Juruna. Revista LIAMES, v. 15, p. 375-392, 2015.

GREEN, D. O sistema numérico da língua Palikúr. In: FERREIRA, M. K. L. (org.). Ideias matemáticas de povos culturalmente distintos. São Paulo: Global, 1994.

GREEN, D. Diferenças entre termos numéricos em algumas línguas indígenas do Brasil. Boletim do Museu Paraense Emílio Goeldi: Série Antropologia, Belém, MPEG, v. 13, 1997.

GREEN, D. Os diferentes termos numéricos das línguas indígenas do Brasil. In: FERREIRA, M. K. L. (org.). Ideias matemáticas de povos culturalmente distintos. São Paulo: Global, 2002.

GREGOR, T. Mehináku: o drama da vida diária em uma aldeia do Alto Xingu. São Paulo: Companhia Editora Nacional, 1982.

INSTITUTO SOCIOAMBIENTAL (ISA). Povos indígenas no Brasil: 2001-2005. São Paulo: Instituto Socioambiental, 2006.

POZZOBON, J. O sistema numérico dos índios Maku. In: FERREIRA, M. K. L. (org.). Ideias matemáticas de povos culturalmente distintos. São Paulo: Global, 2002.

OLIVEIRA, A. Etnomatemática dos Taliáseri: medidores de tempo e sistema de numeração. 2007. Dissertação (Mestrado em Antropologia) - Departamento de Ciências Sociais, Universidade Federal de Pernambuco, Recife, 2007.

POPJES, J.; POPJES, J. Canela-Krahó grammar. In: DERBYSHIRE, D.; PULLUM, G. K. Handbook of Amazonian Languages. v. 1. Berlin: Mouton de Gruyter, 1986. p. 127-199. 